\title{
Fermented Unpolished Black Rice (Oryza sativa L.) Inhibits Melanogenesis via ERK, p38, and AKT Phosphorylation in B16F10 Melanoma Cells
}

\author{
Orrarat Sangkaew and Chulee Yompakdee* \\ Department of Microbiology, Faculty of Science, Chulalongkorn University, Bangkok 10330, Thailand
}

\begin{abstract}
Melanin is a major factor that darkens skin color as one of the defense systems to prevent the harmful effects of UV light. However, darkened skin from the localized or systemic accumulation of melanin is viewed in many cultures as an esthetic problem. Consequentially, searching for antimelanogenic agents from natural sources is very popular worldwide. Previous screening of fermented rice products, obtained from various rice cultivars fermented with different sources of loog-pang (Thai traditional fermentation starter), revealed that the highest ability to reduce the melanin content in B16F10 melanoma cells was from unpolished black rice fermented with a defined starter mixture of microbes isolated from loog-pang E11. The aim of this study was to investigate the mechanism of the fermented unpolished black rice (FUBR) on the inhibition of melanogenesis in B16F10 melanoma cells. The strongest reduction of cellular melanin content was found in the FUBR sap (FUBRS). The melanin reduction activity was consistent with the significant decrease in the intracellular tyrosinase activity. The FUBRS showed no cytotoxic effect to B16F10 melanoma or Hs68 human fibroblast cell lines. It also significantly reduced the transcript and protein expression levels of tyrosinase, tyrosinase-related protein 1 (TYRP-1), TYRP-2, and microphthalmia-associated transcription factor. Furthermore, it induced a significantly increased level of phosphorylated ERK, p38 and Akt signaling pathways, which likely contributed to the negative regulation of melanogenesis. From these results, a model for the mechanism of FUBRS on melanogenesis inhibition was proposed. Moreover, these results strongly suggested that FUBRS possesses antimelanogenesis activity with high potential for cosmeceutical application as a skin depigmenting agent.
\end{abstract}

Keywords: Fermented rice, unpolished black rice, Hom Nin rice, Oryza sativa L., melanogenesis inhibition, melanogenesis-related proteins

Received: March 11, 2020 Accepted: May 6, 2020

First published online: May 8, 2020

* Corresponding author Phone: +66-2-2185096 Fax: +66-2-2527576 E-mail: chulee.y@chula.ac.th

pISSN 1017-7825 elSSN $1738-8872$

Copyright(C) 2020 by The Korean Society for Microbiology and Biotechnology

\section{Introduction}

Melanin is a skin pigment that plays an important role in protection from the harmful effects caused by ultraviolet (UV) light. Overproduction and accumulation of melanin can result in pigmented patches and skin discolorations, such as chloasma, solar lentigo and freckles, that lead to perceived esthetic problems $[1,2]$.

The production of melanin pigment, also called "melanogenesis," is a complicated process regulated by various melanogenesis enzymes, such as tyrosinase, and tyrosinase-related protein 1 (TYRP1) and TYRP2. Among these enzymes, tyrosinase is the essential enzyme in melanogenesis. It catalyzes two initial steps in this process; namely hydroxylation of L-tyrosine into 3,4-dihydroxyphenylalanine (L-DOPA) and the oxidation of L-DOPA into dopaquinone. These melanogenesis enzymes are regulated by microphthalmia-associated transcription factor (MITF) [3-5].

In addition, melanogenesis is modulated by mitogen-activated protein kinase (MAPK) signaling via extracellular signal-regulated kinases (ERK) and p38 MAPK. The phosphorylation of ERK (Thr202/Tyr204) and p38 (Thr180/Tyr182) leads to MITF degradation, which plays a pivotal role in suppressing melanin production [6-8]. The phosphatidylinositol 3-kinase (PI3K)/Akt signaling pathway is also known to be involved in the regulation of melanogenesis, where the phosphorylation of Akt leads to negative regulation of melanogenesis $[9$, 10]. Additionally, UV light radiation causes the synthesis of reactive oxygen species (ROS) that are also involved in the regulation of melanin synthesis. Hence, ROS scavengers and inhibitors of ROS generation may down-regulate melanogenesis [11]

Currently, known depigmenting agents, such as kojic acid, arbutin and linoleic acid, are used as cosmetic agents 
for skin whitening. However, these compounds should be used at a limited dosage due to their cytotoxicity and carcinogenic potential [12]. Accordingly, safer and more effective whitening agents are needed in the cosmetic market.

Natural materials are potentially suitable for the development of effective and safer skin whitening agents in skin care products. Rice (Oryza sativa L.) is one such interesting natural material and is the most important cereal food crop in many Asian countries, including in Thailand [13]. It has been proposed as a potential source of bioactive compounds for health benefits, where a variety of rice cultivars are reported to have medicinal effects [14], such as protection against cytotoxicity, anti-neurodegenerative activity [15], glycogen phosphorylase inhibition [16], and antioxidative activity [17]. Recently, various cultivars of rice have been shown to be able to stimulate melanogenesis [18]. Fermentation is a biotechnological process used as an alternative way to modify, including improve, the biological functionalities of compounds in substrates. Many reports have demonstrated that fermentation can not only enhance the biological activity of a substrate, but can also alter the original bioactive compounds, resulting in a new biological activity [19-21].

Khao-mak a healthy dessert from Thailand, is produced from rice fermented with a microbial starter culture called "loog-pang." It is considered to promote growth in malnourished children, activate bacterial activity, and is used as a dietary supplement. Hence, fermented rice is an interesting natural resource. loog-pang contains yeasts, molds and lactic acid bacteria (LAB), and is mixed with rice to produce fermented rice products [22]. In our preliminary study, various fermented rice samples prepared from different types of rice cultivar and fermented with different sources of loog-pang for $12 \mathrm{~d}$ were screened for their ability to reduce the melanin content in B16F10 melanoma cells. The product from unpolished black rice (UBR; Hom Nin rice) fermented with loog-pang E11 showed the highest reduction activity of melanin content in B16F10 melanoma cells. Thus, in this study, we aimed to further investigate the inhibitory activity of FUBRS in its entirety on melanogenesis in B16F10 melanoma cells and to evaluate its molecular mechanism on the regulation of melanogenesis, including the p38, ERK and Akt signaling pathways.

\section{Materials and Methods \\ Chemicals and Reagents}

All media for cell growth, such as Dulbecco's modified Eagle's medium (DMEM) high glucose, fetal bovine serum (FBS) and trypsin-EDTA (0.25\%) were purchased from Gibco-BRL Inc., USA, while 3-(4,5dimethylthiazol-2-yl)-2,5-diphenyltetrazolium bromide (MTT) and 2,2-diphenyl-1-picrylhydrazyl (DPPH) were purchased from Sigma-Aldrich, USA. Trizol reagent was purchased from Invitrogen, USA. Kojic acid and LDOPA were purchased from Tokyo Chemical Industry Co., Ltd., Japan. The anti-tyrosinase, anti-TYRP-2, antiphospho-p38, anti-p38, anti-ERK1/2, and anti-phospho-ERK1/2 antibodies were purchased from Elabscience Biotechnology Co., Ltd., China.

\section{Isolation and Identification of Microorganisms in the Loog-Pang E11 Microbial Starter}

Appropriate serial dilutions of the loog-pang E11 microbial starter from Chiang Rai province, Thailand, were spread on potato dextrose agar plates for molds and yeast malt extract agar for yeasts and incubated at $30^{\circ} \mathrm{C}$ for 48 $72 \mathrm{~h}$. The LAB were isolated on De Man Rogosa and Sharpe agar with $0.04 \%$ (w/v) bromocresol purple and incubated at $37^{\circ} \mathrm{C}$ under a candle jar. The number of colonies was then counted and expressed as the number of colony-forming units per gram (CFU/g) of culture. The strains of molds, yeasts and LAB were identified by sequencing of the internal transcribed spacer (ITS) region using the ITS1 and ITS4 primers for molds and yeasts, and the $16 \mathrm{~S}$ rRNA gene fragment using the $27 \mathrm{~F}$ and 1492R primers for LAB [23]. Genomic DNA from each strain was isolated as previously described $[22,24]$ and used as the template for ITS or $16 \mathrm{~S}$ rRNA amplification. DNA amplification was performed in a thermocycler with an initial denaturation step for $5 \mathrm{~min}$ at $95^{\circ} \mathrm{C}$, followed by 35 cycles of denaturation for $30 \mathrm{sec}$ at $95^{\circ} \mathrm{C}$, annealing for $30 \mathrm{sec}$ at $55^{\circ} \mathrm{C}$, and extension for $1 \mathrm{~min}$ at $72^{\circ} \mathrm{C}$ and then a final extension for $5 \mathrm{~min}$ at $72^{\circ} \mathrm{C}$. PCR products were sequenced by Macrogen, South Korea. The isolates were identified by matching each sequence to that giving the highest maximum identity score from the NCBI GenBank database using the Basic Local Alignment Search Tool (BLASTn). The sequences of the isolates showed 99.52\%, $100 \%, 99.58 \%$, and $97.58 \%$ sequence similarity to Rhizopus oryzae strain HP25, Saccharomycopsis fibuligera strain PPRI13335, Saccharomyces cerevisiae strain KSD-Yc, and Pediococcus pentosaceus strain IMAU50390, respectively. The sequences of the isolates were deposited in GenBank with accession numbers MN307112, MN307113, MN299328, and MN294560 for R. oryzae strain E1101, Sm. fibuligera strain E1102, S. cerevisiae strain E1103 and $P$. pentosaceus strain E1104, respectively.

\section{Sample Preparation}

Fourty grams of raw UBR purchased from L H Rice International Co., Ltd. (Thailand) was mixed with distilled water at $1: 2(\mathrm{w} / \mathrm{v})$ and autoclaved at $121^{\circ} \mathrm{C}$ for $15 \mathrm{~min}$. The cooked UBR was cooled to room temperature and then fermented as follows: the cooked UBR was mixed with the loog-pang E11 starter culture at 2\% (w/w) and incubated at $30^{\circ} \mathrm{C}$ in a closed sterilized bottle for $12 \mathrm{~d}$. The obtained liquid (rice sap) from the rice fermentation (FUBRS) was collected and kept at $-20^{\circ} \mathrm{C}$ for further study. The residual rice was extracted with hot water as previously described [25]. In brief, $1 \mathrm{~g}$ of rice residual was mixed with $10 \mathrm{ml}$ of distilled water and boiled for $15 \mathrm{~min}$. The sample was then clarified by centrifugation at $11,000 \times g$ for $15 \mathrm{~min}$. The supernatant was kept at $-20^{\circ} \mathrm{C}$ for further study. 


\section{Cell Culture}

B16F10 murine melanoma cell line (ATCC CRL-6475, Lot 63048505) and Hs68 human fibroblast cell line (ATCC CRL-1635, Lot 63691796) were purchased from the American Type Culture Collection (ATCC, USA). The cell lines were certified from ATCC to be mycoplasma contamination undetected. The cell lines were cultured in complete medium [CM; DMEM supplemented with $10 \%$ (v/v) FBS, penicillin $(100 \mathrm{U} / \mathrm{ml})$, and streptomycin $(100 \mathrm{mg} / \mathrm{ml})]$ at $37^{\circ} \mathrm{C}$ under a humidified $95 \%$ air, 5\% $\mathrm{CO}_{2}$ atmosphere. The maintenance and culture of the cell lines were performed according to international guidelines on good cell culture practice [26].

\section{In Vitro Antioxidant Activity Assay}

The antioxidant activity of the FUBRS was determined using the DPPH radical scavenging activity as previously described [27] with modification. The FUBRS at different concentrations and $10 \mu \mathrm{M}$ ascorbic acid were separately incubated with $25 \mathrm{mg} / \mathrm{l} \mathrm{DPPH}$ solution for $30 \mathrm{~min}$ and then the absorbance of the mixed solution at $515 \mathrm{~nm}\left(\mathrm{~A}_{515}\right)$ was measured. The antioxidant activity was calculated as the DPPH scavenging activity as follows: DPPH scavenging activity $(\%)=[(\mathrm{A}-\mathrm{B}) \div \mathrm{A}] \times 100$, where $\mathrm{A}$ and $\mathrm{B}$ are the $\mathrm{A}_{515}$ of $\mathrm{H}_{2} \mathrm{O}$ (as negative control) and the sample, respectively.

\section{Cellular Melanin Content Measurement}

Cellular melanin content was measured as previously described (12). B16F10 cells were plated in 6-well plates $\left(5 \times 10^{4}\right.$ cells/well $)$ and incubated at $37^{\circ} \mathrm{C}$ under a humidified $95 \%$ air, $5 \% \mathrm{CO}_{2}$ atmosphere for $24 \mathrm{~h}$. The cells were then treated with FUBRS and incubated under same condition for $72 \mathrm{~h}$. After incubation, cells were harvested and solubilized in $1 \mathrm{~N}$ sodium hydroxide at $60^{\circ} \mathrm{C}$ for $60 \mathrm{~min}$, and the absorbance of the cell suspension was then measured by spectrophotometer at $405 \mathrm{~nm}\left(\mathrm{~A}_{405}\right)$. The melanin content was expressed as the relative residual melanin (\%) as follows: relative residual melanin $(\%)=[(\mathrm{A} \div \mathrm{B}) \div(\mathrm{C} \div \mathrm{D})] \times 100$, where $\mathrm{A}$ and $\mathrm{C}$ are the $\mathrm{A}_{405}$ values of the treated and untreated cells, respectively, and $\mathrm{B}$ and $\mathrm{D}$ are the protein concentrations of the treated and the untreated cells, respectively. One mM of kojic acid (Tokyo Chemical Industry Co., Ltd., Japan) was used as a positive control.

\section{Cell Viability Assay}

The relative cell viability was determined by the MTT assay. B16F10 cells $\left(1 \times 10^{3}\right.$ cells/ well $)$ and $\mathrm{Hs} 68$ cells $(1 \times$ $10^{5}$ cells/well) were plated in 96 -well plates and incubated at $37^{\circ} \mathrm{C}$ under a humidified $95 \%$ air, $5 \% \mathrm{CO}_{2}$ atmosphere for $24 \mathrm{~h}$. The cells were then treated with varying concentrations of FUBRS [1, 2.5 and $5 \%(\mathrm{v} / \mathrm{v})]$ and incubated at the same condition for $72 \mathrm{~h}$. Then, $10 \mu \mathrm{l}$ of $5 \mathrm{mg} / \mathrm{ml} \mathrm{MTT}$ solution was added and incubated at $37^{\circ} \mathrm{C}$ for $4 \mathrm{~h}$. After incubation, $100 \mu \mathrm{l}$ of isopropanol was added and the absorbance at $540 \mathrm{~nm}\left(\mathrm{~A}_{540}\right)$ was measured. The relative cell viability was then calculated as follows: cell viability $(\%)=(A \div B) \times 100$, where $A$ is the $A_{540}$ value of the treated cells and $B$ is the $A_{540}$ value of the untreated cells.

\section{Intracellular Tyrosinase Activity}

Tyrosinase activity was determined as the L-DOPA oxidase activity as previously described [28]. B16F10 cells were plated in 6 -well plates $\left(5 \times 10^{4}\right.$ cells/well $)$ and incubated at $37^{\circ} \mathrm{C}$ under a humidified $95 \%$ air, $5 \% \mathrm{CO}_{2}$ atmosphere for $24 \mathrm{~h}$. The cells were then treated with FUBRS and incubated under the same condition for $72 \mathrm{~h}$. Then, the cells were washed with ice-cold phosphate-buffered saline (PBS) and completely lysed in lysis buffer [PBS containing $1 \%(\mathrm{v} / \mathrm{v})$ Triton X-100]. After centrifugation at $18,000 \times \mathrm{g}$ for $10 \mathrm{~min}$, the supernatants were harvested and determined for tyrosinase activity. To this end, $90 \mu \mathrm{l}$ of each lysate was mixed with $0.1 \%(\mathrm{w} / \mathrm{v}) \mathrm{L}-$ DOPA (Tokyo Chemical Industry Co., Ltd. ) and incubated at $37^{\circ} \mathrm{C}$ for $1 \mathrm{~h}$. After that, the absorbance of the mixed solution was measured at $475 \mathrm{~nm}\left(\mathrm{~A}_{475}\right)$ and determined as the relative tyrosinase activity (\%) from the following equation: relative tyrosinase activity $(\%)=[(\mathrm{A} \div \mathrm{B}) \div(\mathrm{C} \div \mathrm{D})] \times 100$, where $\mathrm{A}$ and $\mathrm{C}$ are the $\mathrm{A}_{475}$ values of the treated and untreated cells, respectively, and $\mathrm{B}$ and $\mathrm{D}$ are the protein concentrations of the treated and untreated cells, respectively.

Two-Step Quantitative Real-Time Reverse Transcriptase (qrt-RT)-PCR

B16F10 cells were plated in 6-well plates $\left(5 \times 10^{4}\right.$ cells/well) and incubated at $37^{\circ} \mathrm{C}$ under a humidified $95 \%$ air, $5 \% \mathrm{CO}_{2}$ atmosphere for $24 \mathrm{~h}$. The cells were then treated with $5 \%(\mathrm{v} / \mathrm{v})$ of FUBRS and incubated under the same

Table 1. Oligonucleotide primers used for two-step quantitative real-time reverse transcriptase (qrt-RT)-PCR.

\begin{tabular}{|c|c|c|c|}
\hline Primer name & Primer sequence $\left(5^{\prime}-3^{\prime}\right)$ & Annealing temperature & Product size (bp) \\
\hline \multirow[t]{2}{*}{ MITF } & GTATGAACACGCACTCTCGA (Forward) & $49^{\circ} \mathrm{C}$ & 135 \\
\hline & GTAACGTATTTGCCATTTGC (Reverse) & & \\
\hline \multirow[t]{2}{*}{ Tyrosinase } & GTCGTCACCCTGAAAATCCTAACT (Forward) & $52^{\circ} \mathrm{C}$ & 111 \\
\hline & CATCGCATAAAACCTGATGGC (Reverse) & & \\
\hline \multirow[t]{2}{*}{ TYRP1 } & СТTТСТСССТТССТTACTGG (Forward) & $52^{\circ} \mathrm{C}$ & 163 \\
\hline & TCGTACTCTTCCAAGGATTC (Reverse) & & \\
\hline \multirow[t]{2}{*}{ TYRP2 } & TTATATCCTTCGAAACCAGGA (Forward) & $52^{\circ} \mathrm{C}$ & 176 \\
\hline & TTATATCCTTCGAAACCAGGA (Reverse) & & \\
\hline \multirow[t]{2}{*}{$\beta$-actin } & TTCCTTCCTGGGATGGAGT (Forward) & $55^{\circ} \mathrm{C}$ & 105 \\
\hline & CCAGGGCAGTGATCTCCTTC (Reverse) & & \\
\hline
\end{tabular}


condition for $12 \mathrm{~h}$. Total RNA was then extracted using Trizol solution (Invitrogen, USA) according to the manufacturer's instruction. For the first-step RT-PCR, $1 \mu \mathrm{g}$ total RNA was converted into complementary DNA (cDNA) using RevertAid Reverse Transcriptase (Thermo Fisher Scientific, USA). Then, the second-step qrt-PCR reaction was performed using the SsoAdvanced Universal SYBR Green Supermix (Bio-Rad, USA). The plates containing the reaction mixture were transferred to the CFX96 real-time system (Bio-Rad). Thermal cycling was performed at $95^{\circ} \mathrm{C}$ for $3 \mathrm{~min}$, followed by 40 cycles of $95^{\circ} \mathrm{C}$ for $30 \mathrm{sec}$, primer specific temperature $\left(49-55^{\circ} \mathrm{C}\right)$ for $30 \mathrm{sec}$ (see Table 1 ) and $72^{\circ} \mathrm{C}$ for $30 \mathrm{sec}$. The specific primers used for determination of MITF, tyrosinase, TYRP1, TYRP2 and $\beta$-actin gene (as a loading control) transcript levels are shown in Table 1 . The relative gene expression levels were calculated using the $2^{-\Delta \Delta C T}$ method [29].

\section{Protein Quantification by Western Blot Analysis}

$\mathrm{B} 16 \mathrm{~F} 10$ cells were plated in 6-well plates $\left(5 \times 10^{4}\right.$ cells/ well $)$ and incubated at $37^{\circ} \mathrm{C}$ under a humidified $95 \%$ air, $5 \% \mathrm{CO}_{2}$ atmosphere for $24 \mathrm{~h}$. The cells were then treated with FUBRS and incubated under the same condition for

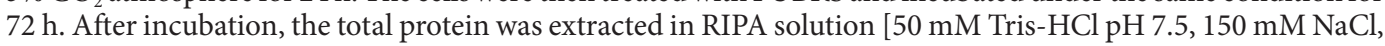
$1 \%(\mathrm{v} / \mathrm{v})$ NP-40, $1 \%(\mathrm{w} / \mathrm{v})$ Na-deoxycholate, $0.1 \%(\mathrm{w} / \mathrm{v})$ sodium dodecyl sulfate (SDS)]. Total protein was separated by SDS-polyacrylamide gel electrophoresis (PAGE) with a $12 \%(\mathrm{w} / \mathrm{v})$ acrylamide resolving gel and then transferred to a PVDF membrane. After blocking with blocking buffer [5\% (w/v) skimmed milk in PBS with $0.1 \%$ (v/v) Tween 20 (PBST)], the membrane was incubated with primary antibody (anti-tyrosinase, anti-TYRP2, antip-ERK1/2, anti-ERK1/2, anti-p-P38, anti-P38, anti-p-Akt, anti-Akt, or anti-GAPDH) (Elabscience Biotechnology Co., Ltd., China) overnight at 1:1000 dilution in blocking buffer. After washing in PBST, the membrane was incubated in anti-rabbit IgG-horseradish peroxidase (HRP) (Cell Signaling Technology, USA) as the secondary antibody at a 1:2000 dilution in blocking buffer. After washing in PBST, immunoreactive bands were visualized with ECL solution (Thermo Fisher Scientific). The band densities were quantified using Bio-Rad Laboratories Quantity One 1-D Analysis Software (V 4.6; Bio-Rad). The relative band densities were determined using those of glyceraldehyde 3-phosphate dehydrogenase (GAPDH) as loading control. Data were expressed as a relative protein expression level.

\section{Statistical Analysis}

Numerical data are shown as the mean \pm one standard error of the mean (SEM) from the indicated number of independent repeats. The statistical significance of differences was analyzed using the GraphPad Prism by oneway analysis of variance (ANOVA), followed by Tukey's multiple comparison test (TMCT). A $p$-value $<0.05$ was accepted as significant.

\section{Results}

\section{UBR Fermented with Defined Starter E11 Decreased Melanin Content in B16F10 Melanoma Cells}

A preliminary screening of various rice cultivars and various sources of microbial starters from loog-pang [22, 30] for the ability of the obtained fermented rice products to reduce the melanin content in B16F10 melanoma cells was performed. It revealed that FUBRS, the sap from UBR (Hom Nin rice) fermented with loog-pang microbial starter E11, gave the highest reduction of melanin content (Figs. 1A and 1B), and this activity was found in the sap but not in the residual rice (Fig. 1C).

The FUBRS at $1 \%, 2.5 \%$, and $5 \%(\mathrm{v} / \mathrm{v})$ dramatically reduced the melanin content $(p<0.001)$ in B16F10 melanoma cells in a dose-dependent manner compared with the untreated cells. In contrast, the unfermented UBR at $5 \%(\mathrm{v} / \mathrm{v})$ significantly increased the melanin content compared to the untreated cells (Figs. 1A and 1B).

The microorganisms contained in the loog-pang E11 were isolated and identified. The identified microbes included the mold R. oryzae strain E1101 at $1 \times 10^{4} \mathrm{CFU} / \mathrm{g}$, the yeasts S. cerevisiae strain E1103 and Sm. fibuligera strain E1102 at $1 \times 10^{3}$ and $2 \times 10^{4} \mathrm{CFU} / g$, respectively, and the LAB P. pentosaceus strain E1104 at $3 \times 10^{8} \mathrm{CFU} / \mathrm{g}$. The mixture of these isolated microbes was designated "defined starter E11" and was used as the fermentation starter for all experiments to produce the FUBRS.

To confirm the role of these isolated microbes from the loog-pang E11 starter culture, the cooked UBR was fermented with the defined starter E11 (R. oryzae, S. cerevisiae, Sm. fibuligera, and P. pentosaceus at a $1 \times 10^{4}, 1 \times$ $10^{3}, 2 \times 10^{4}$, and $3 \times 10^{8} \mathrm{CFU} / \mathrm{g}$ ) for $12 \mathrm{~d}$ at $30^{\circ} \mathrm{C}$ and the harvested ferment sap was tested for its ability to reduce the melanin content in B16F10 melanoma cells. The FUBRS prepared by fermentation of UBR with the defined starter E11 showed a similar ability to reduce melanin in B16F10 melanoma cells as that from the ferment with loog-pang E11 (Fig. 1D), and so fermentation by these microbes (defined starter E11) played a role in producing the active compound(s) that reduce the melanin content in B16F10 melanoma cells.

\section{Antioxidant Activity of the FUBRS}

Antioxidants protect cells from oxidative stress. The antioxidant capacity can be defined as the ability to scavenge ROS leading to a decrease in melanogenesis. To determine whether the FUBRS contained radical scavenging activities, we examined its ability to scavenge DPPH free radicals. For this, DPPH was incubated with the FUBRS at varying concentrations $[0,1,2.5$ and $5 \%(\mathrm{v} / \mathrm{v})]$ and then the $\mathrm{A}_{515}$ was measured. The FUBRS showed a significant DPPH scavenging activity in a dose-dependent manner (Fig. 2), similar to that for ascorbic acid as the positive control (Fig. 2). 


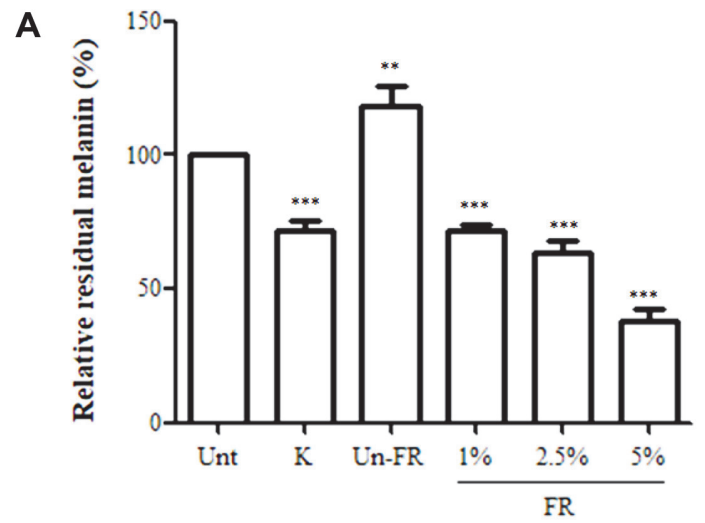

B

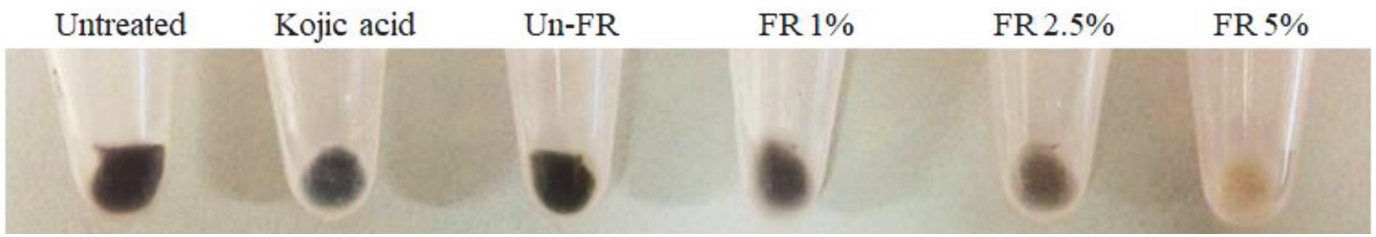

C
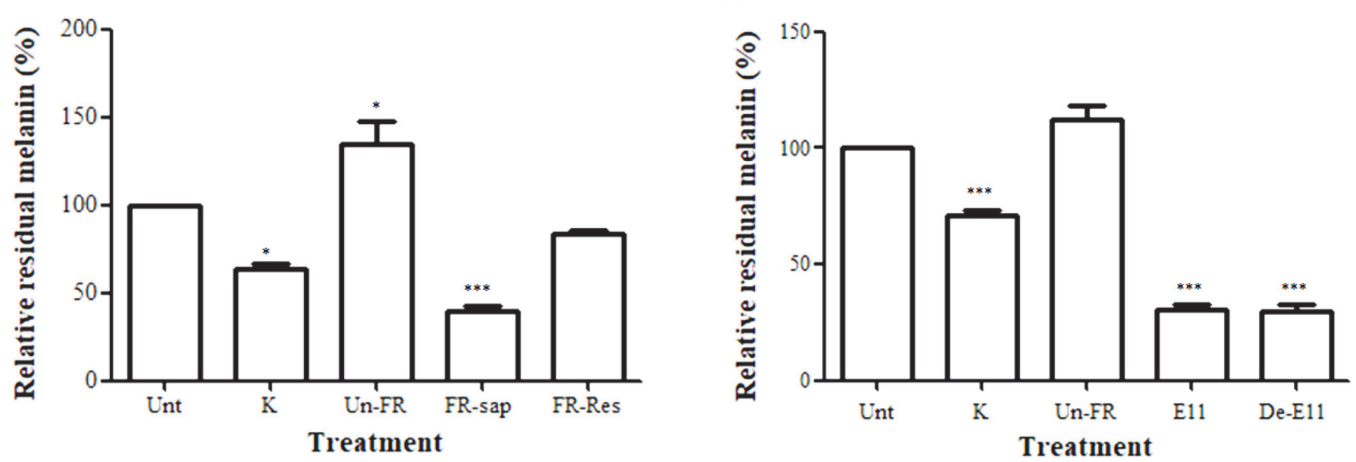

Fig. 1. Reduction of melanin content in B16F10 melanoma cells by FUBRS. B16F10 melanoma cells were treated with $1 \mathrm{mM}$ kojic acid (K) as a positive control, unfermented UBR (Un-FR) at 5\% (v/v) and FUBRS at 1, 2.5, and 5\% (v/v) from fermentation with defined E11. (A) Melanin contents. (B) Visual observation of B16F10 melanoma cells after FUBRS treatment. (C) Residual melanin content in B16F10 melanoma cells after treatment with 5\% (v/v) FUBRS (FR-sap) or FUBR residual rice (FR-Res). (D) Residual melanin content in B16F10 melanoma cells after treatment with 5\% (v/v) FUBRS obtained from loog-pang E11 (E11) or Defined E11 (De-E11). Data are shown as the mean \pm SEM from three independent experiments performed in triplicate. Statistically significant differences compared with untreated cells (Unt) are indicated by ${ }^{*} p<0.05$, ${ }^{* *} p<$ 0.01 , and ${ }^{* * *} p<0.001$.

\section{Non-Cytotoxic Effect of FUBRS on the B16F10 Melanoma and Hs68 Human Fibroblast Cell Lines}

To determine the potential cytotoxicity of FUBRS on skin cells, B16F10 melanoma cells or Hs68 human fibroblast cells were treated with varying concentrations of FUBRS and then evaluated for their relative cell viability using the MTT assay. The results, expressed as the percent viability relative to the untreated control (Fig. 3), revealed that all tested concentrations of FUBRS and 5\% (v/v) of unfermented UBR did not show any significant cytotoxicity to B16F10 melanoma (Fig. 3A) or Hs68 human fibroblast cells (Fig. 3B).

\section{Decreased Cellular Tyrosinase Activity by FUBRS}

Tyrosinase is the essential enzyme in melanogenesis. Thus, we examined the effect of FUBRS on cellular tyrosinase activity. B16F10 melanoma cells were treated with varying concentrations $[1,2.5$, and $5 \%(\mathrm{v} / \mathrm{v})]$ of FUBRS and then the cellular tyrosinase activity was measured. Kojic acid $(1 \mathrm{mM})$ was used as a positive control. The relative tyrosinase activity of B16F10 melanoma cells treated with FUBRS at $1 \%, 2.5 \%$, and $5 \%(\mathrm{v} / \mathrm{v})$ was $63 \%$, $45 \%$, and $24 \%$, respectively, relative to the untreated control (Fig. 4). A similar result was obtained with kojic acidtreated B16F10 cells $(p<0.001)$. In contrast, the unfermented UBR significantly stimulated cellular tyrosinase activity $(p<0.05)$ compared to the untreated cells (Fig. 4). Therefore, FUBRS significantly inhibited cellular tyrosinase activity in a dose-dependent manner $(p<0.001)$. 


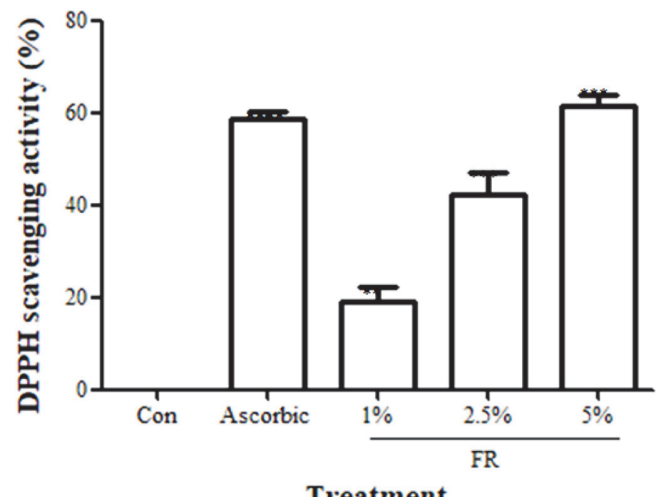

Treatment

Fig. 2. Dose-dependent antioxidant activity of FUBRS. The effect of varying concentrations of FUBRS (FR) and $10 \mu \mathrm{M}$ of ascorbic acid (positive control) on the antioxidant activity were determined from the DPPH radical scavenging activity. Data are shown as the mean \pm SEM from three independent experiments performed in triplicate. Statistically significant differences compared with $\mathrm{H}_{2} \mathrm{O}$ (Control; Con) are indicated by ${ }^{* *} p<0.01$ and ${ }^{* * *} p<0.001$.
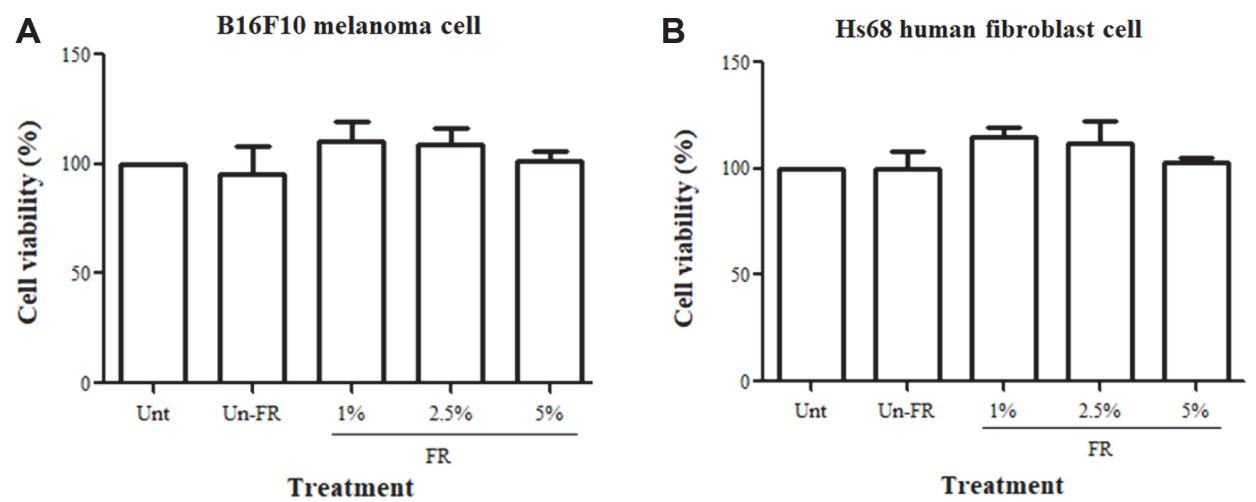

Fig. 3. No cytotoxic effect of FUBRS against (A) B16F10 melanoma or (B) Hs68 human fibroblast cells. The cells were incubated with increasing concentrations of FUBRS (FR) or 5\% (v/v) unfermented UBR (Un-FR). Relative cell viability (\%) was determined by the MTT method compared to untreated cells (Unt). Data are shown as the mean \pm SEM from three independent experiments performed in triplicate.

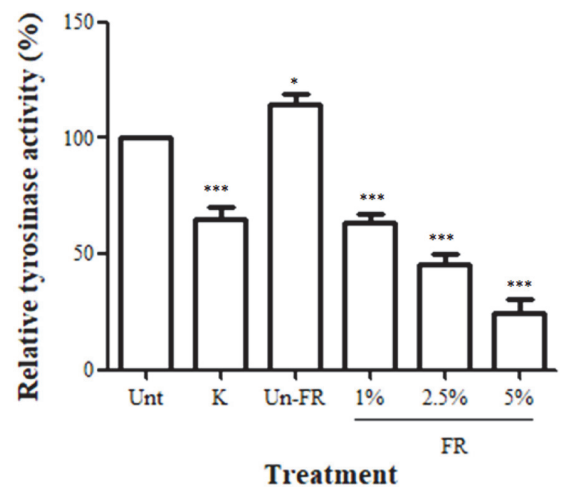

Fig. 4. Decreased cellular tyrosinase activity induced by FUBRS. B16F10 melanoma cells were treated with $1 \mathrm{mM}$ kojic acid $(\mathrm{K})$ as a positive control, unfermented UBR (Un-FR) at $5 \%(\mathrm{v} / \mathrm{v})$ and varying concentrations $[1,2.5$, and $5 \%(\mathrm{v} / \mathrm{v})]$ of FUBRS (FR) prior to determining the tyrosinase activity. Data are shown as the mean \pm SEM from three independent experiments performed in triplicate. Statistically significant differences compared with untreated cells (Unt) are indicated by ${ }^{*} p<0.05$ and ${ }^{* *} p<0.001$.

\section{Decreased Expression Level of Melanogenesis-Related Proteins by FUBRS}

The expression of the melanogenesis-related proteins MITF, tyrosinase, TYRP1, and TYRP2 is essential for melanogenesis. Thus, to elucidate whether the FUBRS affected the expression levels of these melanogenesisrelated proteins, we examined their transcript and protein expression levels in B16F10 melanoma cells after 


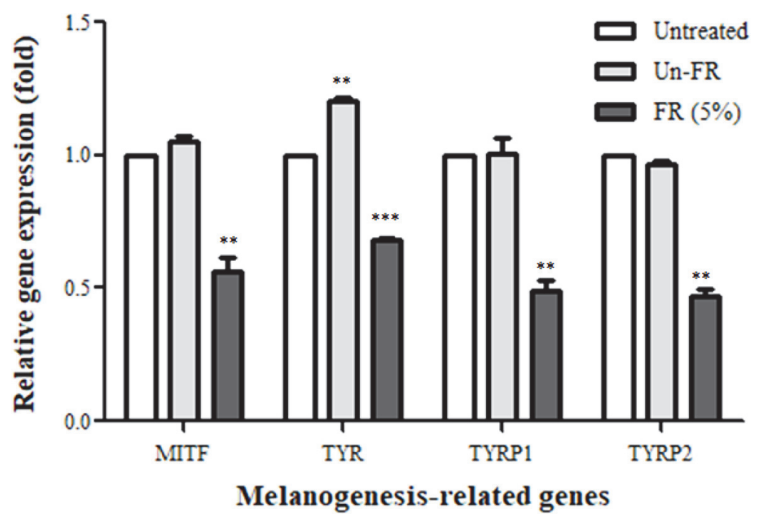

Fig. 5. Reduction of melanogenesis-related gene expression levels by FUBRS. B16F10 melanoma cells were treated with $5 \%(\mathrm{v} / \mathrm{v})$ unfermented UBR (Un-FR) or FUBRS (FR) and then the mRNA levels of MITF, tyrosinase, TYRP1, and TYRP2 were determined by two-step qrtRT-PCR. Values are the means \pm SEM from three independent experiments performed in triplicate. Statistically significant differences compared with untreated cells (Unt) are indicated by ${ }^{* *} p<0.01$ and ${ }^{* * *} p<0.001$.

FUBRS treatment by two-step qrtRT-PCR and western blot analysis, respectively. Treatment with 5\% (v/v) FUBRS suppressed the mRNA expression level of MITF and its downstream genes encoding for tyrosinase, TYRP1, and TYRP2 (Fig. 5). On the other hand, the unfermented UBR treatment significantly increased the mRNA expression level of tyrosinase and had no significant effect on the mRNA expression level of MITF, TYRP1, and TYRP2 compared to the untreated control (Fig. 5).

In addition, the varying concentrations $[1,2.5$, and $5 \%(\mathrm{v} / \mathrm{v})]$ of FUBRS significantly reduced the protein expression levels of tyrosinase and TYRP2 (Fig. 6$)$ in a dose-dependent manner $(p<0.001)$ compared to the untreated cells. It was noted, however, that the potent tyrosinase inhibitor, kojic acid, and the unfermented UBR did not affect the expression levels of tyrosinase and TYRP-2 (Fig. 6).

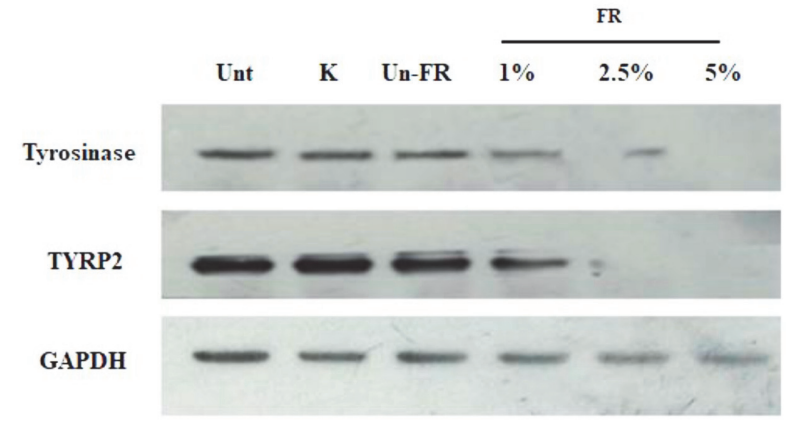

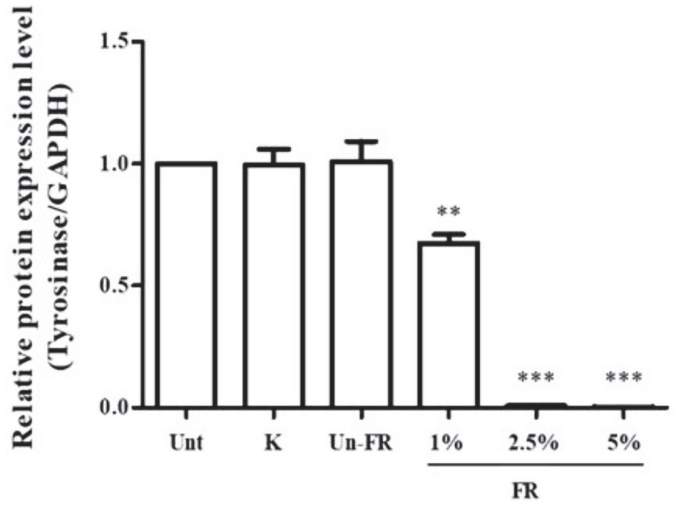

Treatment

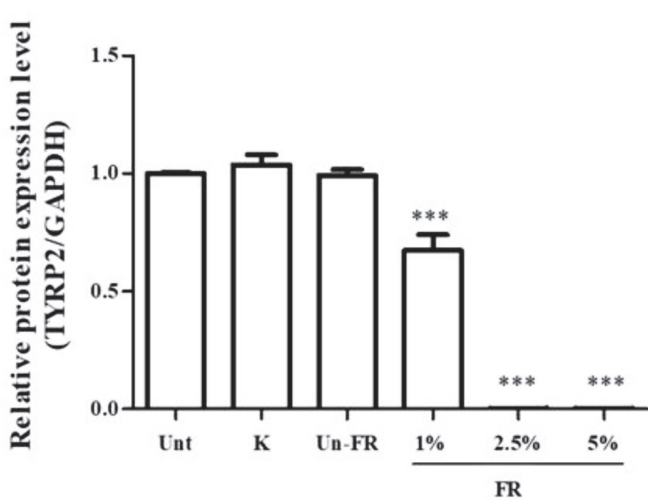

Treatment

Fig. 6. Effect of the FUBRS on the protein expression level of tyrosinase and TYRP2 in B16F10 melanoma cells. B16F10 melanoma cells were treated with $1 \mathrm{mM}$ kojic acid $(\mathrm{K})$ as a positive control, unfermented UBR (Un-FR) at 5\% (v/v) and varying concentrations $[1,2.5$, and $5 \%(\mathrm{v} / \mathrm{v})]$ of FUBRS (FR) for $72 \mathrm{~h}$. The protein expression levels were determined by western blot analysis and normalized to that of GAPDH. Values are the mean \pm SEM from three independent experiments performed in triplicate. Statistically significant differences compared with untreated control (Unt) are indicated by symbols ${ }^{*} p<0.05,{ }^{* *} p<0.01$, and ${ }^{* * *} p<0.001$. 
A

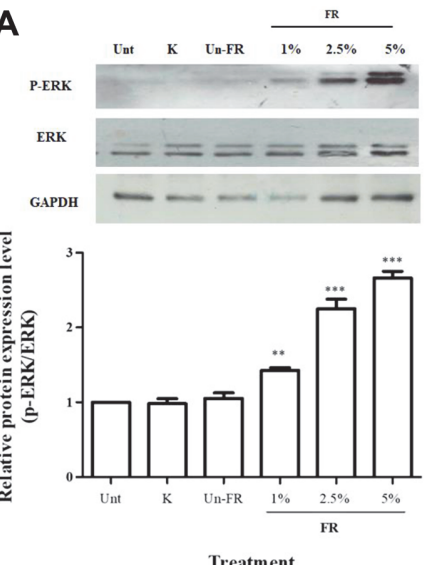

B
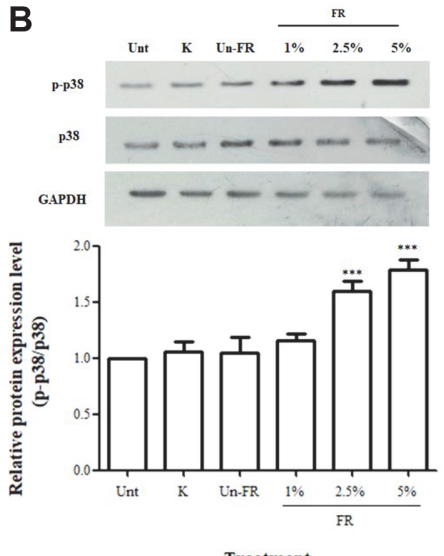

C
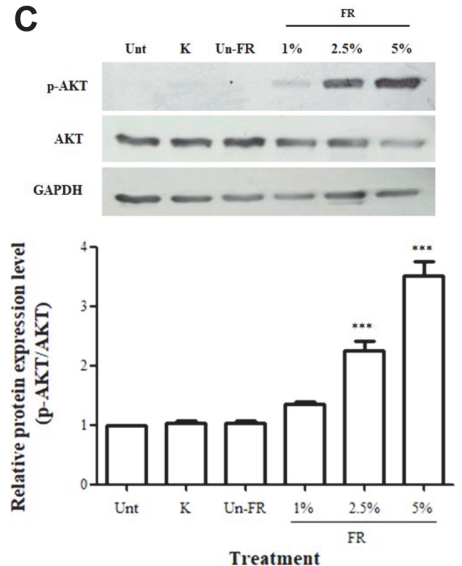

Fig. 7. Effect of FUBRS on phosphorylation of ERK1/2 (p-ERK), p38 (p-p38), and Akt (p-Akt) in B16F10 melanoma cells. B16F10 melanoma cells were treated with $1 \mathrm{mM}$ kojic acid (K), unfermented UBR (Un-FR) at 5\% (v/v) and varying concentrations $[1,2.5$, and $5 \%(\mathrm{v} / \mathrm{v})]$ of FUBRS (FR) for $72 \mathrm{~h}$. The phosphorylation levels of (A) ERK1/2, (B) p38, and (C) Akt were determined by western blot analysis and normalized to the expression of the respective non-phosphorylated protein. Values are the means \pm SEM from three independent experiments performed in triplicate. Statistically significant differences compared with untreated control (Unt) are indicated by symbols ${ }^{* *} p<0.01$ and ${ }^{* *} p<0.001$.

\section{Induced Phosphorylation of Erk1/2, p38 and Akt Signaling Pathways by FUBRS}

Several signaling pathways, including the MAPK (p38 and ERKs) and PI3K/Akt pathway, modulate melanin formation and melanogenic gene expression. To determine the potential modulation of these pathways by FUBRS, B16F10 melanoma cells were exposed to FUBRS and the phosphorylation of these proteins was determined by western blot analysis. The FUBRS-treated cells showed a significantly increased level of phosphorylated ERK1/2 (Fig. 7A), p38 (Fig. 7B), and Akt (Fig. 7C) in a dose-dependent manner $(p<0.001)$, whereas kojic acid and the unfermented UBR did not affect the level of phosphorylation of these proteins (Fig. 7).

\section{Discussion}

Melanin plays a crucial role in protecting skin against the harmful effects from UV light. However, overproduction and accumulation of melanin can create skin problems, such as freckles, age pigment and melasma. Therefore, melanogenesis inhibition has been focused on as an effective method for skin depigmentation and lightening in medicinal and cosmeceutical applications [31,32]. Currently, many compounds, such as arbutin, hydroquinone and kojic acid, are known as melanogenesis inhibitors and are used in skin whitening agents. However, they can induce skin disorders and possess mutagenesis properties [33-35]. Based on these side effects, the search for safer and more effective whitening agents, including from natural sources, is still ongoing in the field of cosmeceuticals research and development.

A previous study showed that fermented rice could reduce the activity of mushroom tyrosinase [36], an in vitro assay that is routinely used for screening for potential inhibitors of melanogenesis. However, many melanogenesis inhibitors obtained from screening against mushroom tyrosinase did not exhibit inhibitory effects on cellular tyrosinase activity (3). In addition, other important properties of a potential inhibitor that are not screened in this in vitro assay include the permeability of the compound into the cells, stability of the compound inside the cells and, especially, cytotoxicity of the compound [37]. Thus, in this study we aimed to elucidate the molecular mechanism of the FUBRS in its entirety on the anti-melanogenesis activity in the B16F10 melanoma cells.

We successfully produced FUBRS with a potent anti-melanogenesis activity (Fig. 1) using UBR (Hom Nin rice) as the substrate and fermenting it using the defined starter E11, containing R. oryzae, S. cerevisiae, Sm. fibuligera, and P. pentosaceus. These were originally isolated from the selected loog-pang E11, a starter of Thai rice-based fermented rice dessert, khao-mak [38] or Thai rice-based alcoholic beverage, Sato [22, 30]. In contrast, the unfermented UBR stimulated melanin production in the B16F10 melanoma cells (Fig. 1A), which is in agreement with a previous report that black rice (Hom Nin rice) stimulated melanogenesis [20].

In contrast to unfermented UBR, the FUBRS strongly inhibited melanogenesis in the B16F10 cells. Thus, during fermentation of UBR bioactive compound(s) could be produced leading to enhancement of various biological activities responsible for the inhibition of melanogenesis. Previously, it was reported that rice bran fermented with fungi or lactic acid bacteria could produce active ingredients or increase levels of active ingredients such as $\alpha$-tocopherol, ascorbic acid, lactic acid, vanillic acid, caffeic acid, protocatechuic acid and 4hydroxybenzoic etc. $[25,39]$, and may have an effect on melanogenesis inhibition. The positive effect of fermentation on increasing some bioactive compounds has been reported previously [40, 41].

Antioxidants that protect cells from oxidative stress are known to play pivotal roles in the inhibition of melanogenesis in B16F10 melanoma cells [42]. The FUBRS contained a dose-dependent antioxidant activity, as determined by the DPPH assay (Fig. 2). This may be from the anthocyanin contained in the UBR [43].

With respect to toxicity to the skin cells, FUBRS at the concentrations up to $5 \%(\mathrm{v} / \mathrm{v})$, the highest concentration 
tested, showed no cytotoxic effect to B16F10 melanoma cells (Fig. 3A) or Hs68 human fibroblast cells (Fig. 3B), suggesting that it is safe for skin cells, and at least for melanoma cells and the fibroblast cells, and so potentially could be used in cosmeceuticals as a whitening agent.

As to the mechanism of inhibition of melanogenesis, FUBRS potently decreased cellular tyrosinase activity in a dose-dependent manner (Fig. 4), consistent with the dramatically decreased cellular melanin content in B16F10 melanoma cells (Fig. 1). Likewise, the fermented rice sap from purple plain rice was previously reported to inhibit mushroom tyrosinase activity (30). In this study, the FUBRS showed an inhibitory effect on tyrosinase activity (Fig. 4) and on the expression level of tyrosinase (Figs. 5 and 6). In contrast, the unfermented UBR showed the opposite effect, with a significant stimulation of tyrosinase activity (Fig. 4) and tyrosinase gene expression (Fig. 5). This contrasting effect between the fermented and unfermented UBR emphasized the important role of the defined starter E11 on transformation of the compound(s) in the rice substrate to form the biological activity.

The FUBRS significantly reduced the transcript expression level of MITF, a major transcription factor in the regulation of melanogenic enzyme that plays a critical role in melanin biosynthesis [44]. Likewise, FUBRS reduced the transcript level of enzymes downstream of MITF, including tyrosinase, TYRP1, and TYRP2 (Fig. 5), and significantly reduced the expression of tyrosinase and TYRP2 in a dose-dependent manner at the translational level (Fig. 6). In contrast, kojic acid, a well-known inhibitor of tyrosinase, did not affect the expression levels of tyrosinase, TRP-1, TRP-2, and MITF. These results suggested that FUBRS has different melanogenesis inhibition mechanisms from kojic acid. The FUBRS likely reduced melanogenesis by inhibiting tyrosinase activity and the expression levels of tyrosinase, TYRP1, and TYRP2 via inhibiting expression of MITF in B16F10 melanoma cells.

Previous studies have also shown that the MAPK pathway, including ERK and p38, play important regulatory roles during melanogenesis [45], where melanogenesis inhibitors activated the phosphorylation of ERK and p38. These phosphorylations resulted in the phosphorylation of MITF at serine 73 and subsequent ubiquitindependent proteasomal degradation [46]. Accordingly, we examined the phosphorylation level of ERK and p38 in B16F10 melanoma cell after treatment with FUBRS. The results revealed that FUBRS activated the phosphorylation of ERK and p38 (Figs. 7A and B).

Besides the MAPK pathway, PI3K/Akt causes MITF transcription to bind to the target sequence and induce melanogenesis. Hence, inhibition of the phosphorylation of Akt leads to the increasing of MITF expression resulting in melanin synthesis [47]. It has been reported that sesamol elevated the phosphorylation of Akt, possibly by reducing MITF transcription, and this led to the inhibition of melanin production and tyrosinase activity [48]. In our study, FUBRS significantly increased the level of phosphorylated Akt (Fig. 7C). Taken

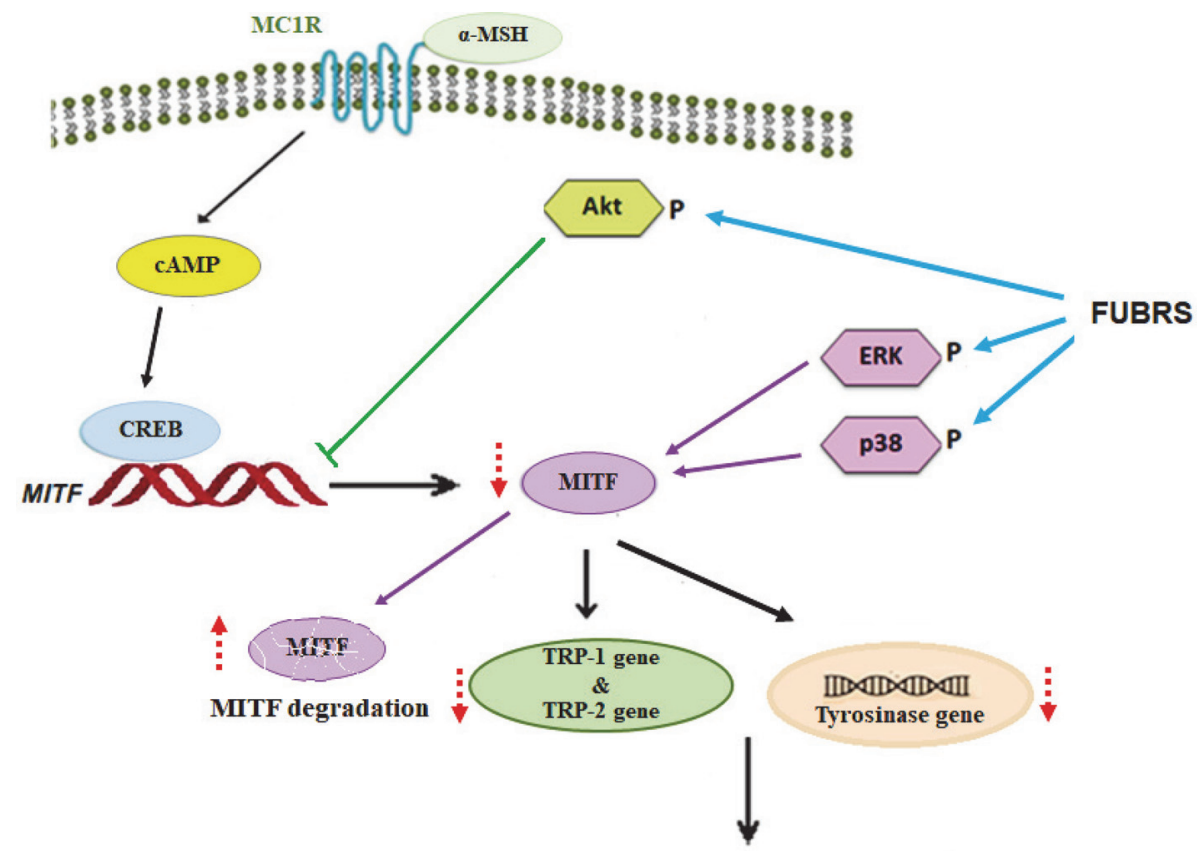

\section{Melanogenesis:}

Fig. 8. Schematic description of the inhibition of melanogenesis in B16F10 melanoma cells upon FUBRS treatment. Symbols: $\longleftarrow$ represents activation, $\vdash$ represents inhibition, blue arrow represents the effect of FUBRS on the phosphorylation of ERK, p38 and Akt, red dash arrow represents results from the phosphorylation of ERK, p38 and Akt. The FUBRS stimulated phosphorylation of ERK and p38 leading to MITF degradation (purple line) and it also stimulated phosphorylation of Akt (green line) leading to the decreasing of MITF expression. The results from increasing phosphorylation of ERK, p38 and AKT led to decrease in the MITF level, thus, the expression of genes downstream of MITF such as tyrosinase, TYRP1, TYRP2 were decreased. 
together, the results from Fig. 7A, 7B and 7C demonstrate that, FUBRS may reduce the level of MITF by increasing MITF degradation as a result from increased phosphorylation of ERK and p38 and also reduce MITF transcription as a result of increased phosphorylation of Akt.

The present study showed that the fermentation of UBR (Hom Nin rice) with the defined mixed culture of $R$. oryzae, S. cerevisiae, Sm. fibuligera, and P. pentosaceus to form FUBRS resulted in a potent reduction of cellular melanin content and antioxidant activity. The FUBRS had an antioxidant activity that may have the ability to scavenge ROS. It is known that ROS stimulates alpha-melanocyte stimulating hormone production in keratinocytes and binds to the melanocortin 1 receptor on melanoma cells leading to melanogenesis $[49,50]$. In addition, it inhibited melanin biosynthesis by stimulating phosphorylation of ERK and p38 leading to MITF degradation and also stimulating phosphorylation of Akt leading to a reduction of MITF expression. As a consequence, the expression of genes downstream of MITF including TYRP1, TYRP2, and tyrosinase genes, was reduced. A schematic diagram of the potential mechanisms of FUBRS on melanogenesis is summarized in Fig. 8.

The mechanism for the melanogenesis inhibition by FUBRS appears to be more complex than that of kojic acid, the known tyrosinase inhibitor. Therefore, the isolation and identification of major bioactive compounds from the FUBRS crude extract would be the next step of our study. This is under investigation and will be published elsewhere.

Overall, the FUBRS obtained in this study has high potential for further cosmeceuticals application as a depigmenting agent. The role of the defined starter E11 on producing bioactive compounds with anti-melanogenesis is also under investigation.

\section{Acknowledgments}

The authors thank Chulalongkorn University: CU-GI_62_02_23_01 and the 90 ${ }^{\text {th }}$ Anniversary of Chulalongkorn University Fund for financial support.

\section{Conflict of Interest}

The authors have no financial conflicts of interest to declare.

\section{References}

1. Hearing VJ. 2005. Biogenesis of pigment granules: a sensitive way to regulate melanocyte function. J. Dermatol. Sci. 37: 3-14.

2. Hearing VJ. 2011. Determination of melanin synthetic pathways. J. Invest. Dermatol. 131: E8-E11.

3. Chan CF, Huang CC, Lee MY, Lin YS. 2014. Fermented broth in tyrosinase- and melanogenesis inhibition. Molecules 19: 1312213135.

4. Chang TS. 2009. An updated review of tyrosinase inhibitors. Int. J. Mol.Sci. 10: 2440-2475

5. Smit N, Vicanova J, Pavel S. 2009. The hunt for natural skin whitening agents. Int. J. Mol. Sci. 10: 5326-5349.

6. Alam MB, Bajpai VK, Lee J, Zhao P, Byeon JH, Ra JS, et al. 2017. Inhibition of melanogenesis by jineol from Scolopendra subspinipes mutilans via MAP-Kinase mediated MITF downregulation and the proteasomal degradation of tyrosinase. Sci. Rep. 7: 45858.

7. Chung SY, Seo YK, Park JM, Seo MJ, Park JK, Kim JW, et al. 2009. Fermented rice bran downregulates MITF expression and leads to inhibition of alpha-MSH-induced melanogenesis in B16F1 melanoma. Biosci. Biotechnol. Biochem. 73: 1704-1710.

8. Yao C, Oh JH, Oh IG, Park CH, Chung JH. 2013. Shogaol inhibits melanogenesis in B16 mouse melanoma cells through activation of the ERK pathway. Acta Pharmacol. Sin. 34: 289-294.

9. Jeong HS, Gu GE, Jo AR, Bang JS, Yun HY, Baek KJ, et al. 2015. Baicalin-induced Akt activation decreases melanogenesis through downregulation of microphthalmia-associated transcription factor and tyrosinase. Eur. J. Pharmacol. 761: 19-27.

10. Saito H, Yasumoto K, Takeda K, Takahashi K, Yamamoto H, Shibahara S. 2003. Microphthalmia-associated transcription factor in the Wnt signaling pathway. Pigment Cell Res. 16: 261-265.

11. Funasaka Y, Komoto M, Ichihashi M. 2000. Depigmenting effect of alpha-tocopheryl ferulate on normal human melanocytes. Pigment Cell Res. 13 Suppl 8: 170-174.

12. Kwak YJ, Kim KS, Kim KM, Yu HY, Chung E, Kim SJ, et al. 2011. Fermented Viola mandshurica inhibits melanogenesis in B16 melanoma cells. Biosci. Biotechnol. Biochem. 75: 841-847.

13. Chunta S, Prathepha P, Thiha, Jongdee B. 2014. Nuances of traditional knowledge in utilization of rice landraces by a farming community in North-Eastern Thailand. Indian J. Tradit Know. 13: 473-483.

14. Vichapong J, Sookserm M, Srijesdaruk V, Swatsitang P, Srijaranai S. 2010. High performance liquid chromatographic analysis of phenolic compounds and their antioxidant activities in rice varieties. Lwt-Food Sci Technol. 43: 1325-1330.

15. Kim D-O, Heo HJ, Kim YJ, Yang HS, Lee CY. 2005. Sweet and sour cherry phenolics and their protective effects on neuronal cells. J. Agr. Food Chem. 53: 9921-9927.

16. Jakobs S, Fridrich D, Hofem S, Pahlke G, Eisenbrand G. 2006. Natural flavonoids are potent inhibitors of glycogen phosphorylase. Mol. Nutr. Food Res. 50: 52-57.

17. Kano M, Takayanagi T, Harada K, Makino K, Ishikawa F. 2005. Antioxidative activity of anthocyanins from purple sweet potato, Ipomoera batatas cultivar Ayamurasaki. Biosci. Biotechnol. Biochem. 69: 979-988.

18. Soradech S, Reungpatthanaphong P, Tangsatirapakdee S, Panaphong K, Thammachat T, Manchun, S. et al. 2016. Radical scavenging, antioxidant and melanogenesis stimulating activities of different species of rice (Oryza sativa L.) extracts for hair treatment formulation. Thai J. Pharmaceutical Sci. 40: 92-95.

19. Lin YW, Chiang BH. 2008. Anti-tumor activity of the fermentation broth of Cordyceps militaris cultured in the medium of Radix astragali. Process Biochem. 43: 244-250.

20. Miyake Y, Fukumoto S, Okada M, Sakaida K, Nakamura Y, Osawa T. 2005. Antioxidative catechol lignans converted from sesamin and sesaminol triglucoside by culturing with Aspergillus. J. Agric. Food Chem. 53: 22-27.

21. Nakano D, Kwak CJ, Fujii K, Ikemura K, Satake A, Ohkita M, et al. 2006. Sesamin metabolites induce an endothelial nitric oxidedependent vasorelaxation through their antioxidative property-independent mechanisms: Possible involvement of the metabolites in the antihypertensive effect of sesamin. J. Pharmacol. Exp. Ther. 318: 328-335.

22. Taechavansonyoo A, Thaniyavarn J, Yompakdee C. 2013. Identification of the molds and yeasts characteristic of a superior Loogpang, starter of Thai rice-based alcoholic beverage Sato. Asian J. Food Agro-Industry 6: 24-38. 
23. Zhao M, Zhang DL, Su XQ, Duan SM, Wan JQ, Yuan WX, et al. 2015. An integrated metagenomics/metaproteomics investigation of the microbial communities and enzymes in solid-state fermentation of Pu-erh tea. Sci. Rep. 5: 10117.

24. Alimolaei M, Golchin M. 2016. An efficient DNA extraction method for Lactobacillus casei, a Difficult-to-Lyse bacterium. Int. J. Enteric. Pathog. 4: e32472.

25. Abd Razak DL, Abd Rashid NY, Jamaluddin A, Sharifudin SA, Abd Kahar A, Long K. 2017. Cosmeceutical potentials and bioactive compounds of rice bran fermented with single and mix culture of Aspergillus oryzae and Rhizopus oryzae. J. Saudi Soc. 16: 127-134.

26. Coecke S, Balls M, Bowe G, Davis J, Gstraunthaler G, Hartung T, et al. 2005. Guidance on good cell culture practice - A report of the second ECVAM task force on Good Cell culture practice. Atla-Altern Lab Anim. 33: 261-287.

27. Tachibana Y, Kikuzaki H, Lajis NH, Nakatani N. 2001. Antioxidative activity of carbazoles from Murraya koenigii leaves. J. Agr. Food Chem. 49: 5589-5594.

28. Jun HJ, Lee JH, Cho BR, Seo WD, Kang HW, Kim DW, et al. 2012. Dual inhibition of gamma-oryzanol on cellular melanogenesis: inhibition of tyrosinase activity and reduction of melanogenic gene expression by a protein kinase a-dependent mechanism. J. Nat. Prod. 75: 1706-1711.

29. Livak KJ, Schmittgen T. 2001. Analysis of relative gene expression data using real-time quantitative PCR and the 2-DDCt method. Methods. 25: 402-408

30. Luangkhlaypho A, Pattaragulwanit K, Leepipatpiboon N, Yompakdee C. 2014. Development of a defined starter culture mixture for the fermentation of sato, a Thai rice-based alcoholic beverage. Scienceasia 40: 125-134.

31. Khan MT. 2012. Novel tyrosinase inhibitors from natural resources - their computational studies. Curr. Med. Chem. 19: $2262-2272$.

32. Liang C, Lim JH, Kim SH, Kim DS. 2012. Dioscin: a synergistic tyrosinase inhibitor from the roots of Smilax China. Food Chem. 134: 1146-1148.

33. Findlay GH, de Beer HA. 1980. Chronic hydroquinone poisoning of the skin from skin-lightening cosmetics. A South African epidemic of ochronosis of the face in dark-skinned individuals. S. Afr. Med. J. 57: 187-190.

34. O'Donoghue JL. 2006. Hydroquinone and its analogues in dermatology - a risk-benefit viewpoint. J. Cosmet. Dermatol. 5: $196-203$.

35. Parvez S, Kang M, Chung HS, Cho C, Hong MC, Shin MK, et al. 2006. Survey and mechanism of skin depigmenting and lightening agents. Phytother. Res. 20: 921-934.

36. Manosroi A, Ruksiriwanich W, Kietthanakorn B-o, Manosroi W, Manosroi J. 2011. Relationship between biological activities and bioactive compounds in the fermented rice sap. Food Res. Int. 44: 2757-2765.

37. Sangkaew A, Krungkrai J, Yompakdee C. 2018. Development of a high throughput yeast-based screening assay for human carbonic anhydrase isozyme II inhibitors. AMB Express. 8: 124

38. de Llanos R, Querol A, Peman J, Gobernado M, Fernandez-Espinar MT. 2006. Food and probiotic strains from the Saccharomyces cerevisiae species as a possible origin of human systemic infections. Int. J. Food Microbiol. 110: 286-290.

39. Abd Rashid NY, Abd Razak D, Jamaluddin A, Sharifudin S, Long K. 2015. Bioactive compounds and antioxidant activity of rice bran fermented with lactic acid bacteria. Malays J. Microbiol. 11: 156-162.

40. Cheng k-C, Wu J-Y, Lin J-T, Liu W-H. 2013. Enhancements of isoflavone aglycones, total phenolic content, and antioxidant activity of black soybean by solid-state fermentation with Rhizopus spp. Eur. Food Res. Technol. 236:1107-1113.

41. Lee IH, Hung Y-H, Chou C-C. 2008. Solid-state fermentation with fungi to enhance the antioxidative activity, total phenolic and anthocyanin contents of black bean. Int. J. Food Microbiol. 121: 150-156.

42. Kim YJ, Kang KS, Yokozawa T. 2008. The anti-melanogenic effect of pycnogenol by its anti-oxidative actions. Food Chem. Toxicol. 46: 2466-2471.

43. Hao J, Zhu H, Zhang ZQ, Yang SL, Li HR. 2015. Identification of anthocyanins in black rice (Oryza sativa L.) by UPLC/Q-TOF-MS and their in vitro and in vivo antioxidant activities. J. Cereal Sci. 64: 92-99.

44. Busca R, Ballotti R. 2000. Cyclic AMP a key messenger in the regulation of skin pigmentation. Pigment Cell Res. 13: 60-69.

45. Englaro W, Bertolotto C, Busca R, Brunet A, Pages G, Ortonne JP, et al. 1998. Inhibition of the mitogen-activated protein kinase pathway triggers B16 melanoma cell differentiation. J. Biol. Chem. 273: 9966-9970.

46. Kim DS, Hwang ES, Lee JE, Kim SY, Kwon SB, Park KC. 2003. Sphingosine-1-phosphate decreases melanin synthesis via sustained ERK activation and subsequent MITF degradation. J. Cell Sci. 116: 1699-1706.

47. Oka M, Nagai H, Ando H, Fukunaga-Kalabis M, Matsumura M, Araki K, et al. 2000. Regulation of melanogenesis through Phosphatidylinositol 3-Kinase-Akt pathway in human G361 melanoma Cells. J. Invest. Dermatol. 115: 699-703.

48. Wu PY, You YJ, Liu YJ, Hou CW, Wu CS, Wen KC, et al. 2018. Sesamol inhibited melanogenesis by regulating melanin-related signal transduction in B16F10 Cells. Int. J. Mol. Sci. 19: 1108

49. Dong Y, Cao J, Wang H, Zhang J, Zhu Z, Bai R, et al. 2010. Nitric oxide enhances the sensitivity of alpaca melanocytes to respond to alpha-melanocyte-stimulating hormone by up-regulating melanocortin-1 receptor. Biochem. Biophys. Res. Commun. 396: 849-853.

50. Horikoshi T, Nakahara M, Kaminaga H, Sasaki M, Uchiwa H, Miyachi Y. 2000. Involvement of nitric oxide in UVB-induced pigmentation in guinea pig skin. Pigment Cell Res. 13: 358-363. 